\title{
Respeto y relaciones inter-generacionales en la Escuela Secundaria: sentidos que jóvenes de sectores populares le atribuyen al trato respetuoso por parte de las y los adultos educadores
}

\section{Respect and Intergenerational Relationships in Secondary School: senses that young people from popular sectors attribute to respectful treatment by adult educators}

Gabriel Rosales*

Recibido: 6 de abril de 2020 Aceptado: 1 de junio de 2020 Publicado: 31 de julio de 2020

To cite this article: Rosales, G. (2020). Respeto y relaciones inter-generacionales en la Escuela Secundaria: sentidos que jóvenes de sectores populares le atribuyen al trato respetuoso por parte de las y los adultos educadores. Márgenes, Revista de Educación de la Universidad de Málaga, 1 (2), 107-119

DOI: https://doi.org/10.24310/mgnmar.v1i2.8463

\section{RESUMEN}

Este escrito surge en el marco del Proyecto de Investigación "Relaciones inter-generacionales en instituciones educativas formales: experiencias de niños/as, jóvenes y adultos/as”, radicado en la FCH-UNSL. El proyecto tiene por objeto general indagar cómo se (re)construyen los vínculos inter-generacionales en escenarios educativos formales, a partir de explorar las experiencias que de estas relaciones tienen niños/as, jóvenes y adultos/as. En este marco de reflexión, este trabajo expondrá particularmente los sentidos que jóvenes de sectores populares que asisten a escuelas secundarias de la Ciudad de San Luis (Argentina) han construido en relación a la idea de "respeto" en los vínculos que establecen con las y los adultos educadores de sus escuelas. Para indagar este tópico analizamos un corpus conformado por 250 encuestas y 25 entrevistas realizadas a jóvenes.

Según lo muestran investigaciones nacionales e internacionales recientes, la noción de respeto emerge como un vector privilegiado para analizar el modo en que los vínculos inter-generacionales y pedagógicos se transforman en la actualidad pues visibiliza -entre otros aspectos- vivencias, necesidades y reclamos juveniles que tensionan los vínculos escolares. En este trabajo, particularmente, identificamos dos grandes núcleos de sentido vinculados a cómo las y los estudiantes entienden la noción de respeto: el respeto unidireccional o tradicional, y el respeto bidireccional o emergente.

Palabras clave: respeto; relaciones inter-generacionales; escuela secundaria

\section{ABSTRACT}

This writing arises in the Research Project "Inter-generational relations in formal educational institutions: experiences of children, youth and adults”, based on the FCH-UNSL. The project's general objective is to investigate how inter-generational links are (re) constructed in formal educational settings, by exploring the 


\section{N V E S T I G A C I Ó N}

experiences that children, youth and adults have of these relationships. In this framework of reflection, this work will particularly expose the meanings that young people from popular sectors who attend secondary schools in the City of San Luis have built in relation to the idea of "respect" in the links they establish with adult educators from their schools. To investigate this topic, we analyzed a corpus made up of 250 surveys and 25 interviews with young people.

As recent national and international research shows, the notion of respect emerges as a privileged vector to analyze the way in which inter-generational and pedagogical links are transformed today because it makes visible, among other aspects, youth experiences, needs and claims that stress school ties. In this work, in particular, we identify two large nuclei of meaning linked to how students understand the notion of respect: one-way or traditional respect, and two-way or emerging respect.

Keywords: respect; intergenerational relationships; secondary school

\section{INTRODUCCIÓN}

Esta ponencia surge en el marco del Proyecto de Investigación "Relaciones inter-generacionales en instituciones educativas formales: experiencias de niños/as, jóvenes y adultos/as”, radicado en la Facultad de Ciencias Humanas-Universidad Nacional de San Luis (Argentina). El proyecto tiene como objetivo general indagar cómo se (re)construyen los vínculos inter-generacionales en escenarios educativos formales, a partir de explorar las experiencias que de estas relaciones tienen niños/as, jóvenes y adultos/as. En este marco de reflexión, este trabajo expondrá particularmente los sentidos que jóvenes de sectores populares ${ }^{1}$ que asisten a escuelas secundarias ${ }^{2}$ de la Ciudad de San Luis han construido en relación a la idea de "respeto" en los vínculos que establecen con las y los adultos educadores de sus escuelas.

El corpus empírico que analizaremos está conformado por 250 encuestas y 25 entrevistas breves realizadas a jóvenes. Estas encuestas y entrevistas fueron tomadas por docentes que trabajan en escuelas secundarias de sectores populares en el marco de un curso de actualización profesional que dictamos desde el proyecto de investigación. Como parte de un proceso de reflexión sobre la propia práctica, se les propuso a estos docentes que indagaran cómo entendían sus estudiantes la noción de respeto en el marco de las relaciones que establecían con las y los docentes de sus escuelas. Para ello se construyó colectivamente una única encuesta, se la aplicó en cursos de los dos últimos años de sus escuelas, se realizó un primer análisis de datos y luego se les pidió que profundizaran en algunos aspectos emergentes a través de entrevistas breves. La única restricción que se puso en el proceso, fue que los instrumentos de recogida de la información no podían ser aplicados en los cursos donde ellos/as se desempeñaran como docentes de manera directa, sino en el de algún colega de su misma institución.

\footnotetext{
1 Por jóvenes de sectores populares se alude, en sentido amplio, a chicos y chicas de clase baja o media baja, cuyos progenitores se desempeñan en trabajos manuales de carácter informal (no registrado) o bien se encuentran desempleados y perciben subsidios estatales o planes sociales. Muchos de estos hogares se encuentran bajo la línea de la pobreza, es decir perciben ingresos menores a 39.000 pesos argentinos (572 dólares o 525 euros). En un informe reciente (mayo 2020) UNICEF Argentina dio a conocer su estimación sobre el alcance que la pobreza tendrá en niños, niñas y adolescentes hacia fin de año, según esta proyección llegaría al 58,6\%.
}

2 En Argentina al nivel secundario asisten jóvenes de entre 13-17/18 años. 


\section{N V E S T I G A C I Ó N}

Debido a las características de este abordaje, entendemos que este estudio es de naturaleza exploratoria. Esperamos, a partir de este primer análisis panorámico, identificar algunas líneas de indagación que nos permitan profundizar en abordajes posteriores cómo significan la idea de respeto las y los jóvenes, considerándola en el ámbito más amplio de las relaciones intergeneracionales que establecen con sus docentes. Relaciones que, como lo muestran diferentes investigaciones, se encuentran un profundo proceso de redefinición.

\section{RELACIONES INTER-GENERACIONALES Y RESPETO EN LA ESCUELA SECUNDARIA}

"Los actos que vehiculizan el respeto -los actos de reconocimiento de los otros- son exigentes y oscuros." Richard Sennett

El problema de los procesos de reconocimiento subjetivo e intersubjetivo en la vida social, particularmente de aquellos sujetos cuyas situaciones vitales se encuentran marcadas por desigualdades sociales y económicas constituyen, desde hace algunos años, un tópico de interés de las ciencias sociales (Bourgois, 2015). Por otra parte, los procesos de reconocimiento que se dan específicamente en ámbitos escolares también han comenzado a indagarse recientemente (Núnez, 2013; Paulín y Martínez, 2014; Aleu, 2017; Silva 2018). En este último caso, la búsqueda surge jalonada por los conflictivos cambios que viven los procesos de reproducción cultural institucionalizados en las escuelas contemporáneas, particularmente las que forman parte del nivel secundario.

Una de las preocupaciones centrales tiene que ver con las tensiones y conflictos existentes en las relaciones inter e intra-generacionales. La crisis de la autoridad pedagógica, entendiéndola como crisis de la legitimidad adulta ante las nuevas generaciones, constituye una expresión de estas discordancias y, estrechamente vinculado con esto, surge el problema de las prácticas respetuosas o irrespetuosas entre adultos y jóvenes pues, como lo analizan varios estudios, las posibilidades de re-legitimación de las y los docentes pasan por plantearse la pregunta por la reciprocidad y el respeto en los vínculos con sus estudiantes (Aleu, 2008; Rosales, 2013; Aleu, 2017).

“Respeto a los que me respetan" suelen decir con frecuencia los y las jóvenes, por ello resulta de interés indagar los sentidos que le atribuyen a esta noción como clave para pensar los procesos de reconocimiento intersubjetivo que acontecen o fallan en la cotidianidad escolar.

Como bien señala Todorov "La necesidad de reconocimiento es el hecho humano constitutivo. El hombre no existe antes que la sociedad, y lo humano está fundado en lo interhumano" (2008, p. 42). Por ello dependemos, para existir, no sólo de alimentación, abrigo y cuidado, sino también de las miradas de otros que nos confirman -con su aprobación o desaprobación- quienes somos. Es más, según este autor, somos esas miradas que nos confirman en tanto nuestra conciencia e identidad, las imágenes que construimos acerca de quiénes somos, se constituyen a partir de interiorizar las valoraciones que de nosotros hacen otros u otras.

Esta necesidad de reconocimiento implica una dependencia necesaria de los vínculos sociales. No podemos ser sino es en el marco de relaciones que nos brindan el sentimiento de existencia y, en este sentido, el vínculo inter-generacional constituye el ámbito donde se da el acto de 


\section{N V E S T I G A C I Ó N}

reconocimiento fundante: acontece al inicio de la vida y se concreta por un otro/a respecto del cual nos une un vínculo asimétrico, dispar, marcado por una profunda indefensión y necesidad de protección, cuidado y guía. También es un acto de reconocimiento mutuo: pues a la vez que alguien es reconocido -el niño/a-, alguien se siente reconocido al reconocer -la madre o padre(Todorov, 2008; Sennett, 2003).

Esta necesidad de reconocimiento, entendida como invariante antropológica (Todorov, 2008), resulta transhistórica: constitutiva por definición de lo humano. Lo que resulta histórico, relativo a cada contexto y cultura, son los modos en que las diferentes sociedades definen los actos de reconocimiento e instituyen vías para efectivizarlos. Estos procesos implican la mediación de instancias institucionales y organizativas. Las instituciones funcionan como principios generales y abstractos construidos históricamente y propios de las diferentes culturas que se concretan en organizaciones específicas. En el marco de estas múltiples traducciones, los sujetos se inscriben en una trama simbólica e imaginaria que los constituye como tales, que tiene efectos concretos en las formas de pensamiento y de relación entre unos y otros (Aleu, 2017).

Considerando el desarrollo histórico de las sociedades occidentales, el acontecimiento de la revolución francesa instituyó una noción fundante de la subjetividad moderna imprescindible de considerar si se quiere comprender cómo los individuos viven y significan la noción de respeto o irrespeto: la idea de que los seres humanos somos esencialmente libres e iguales en dignidad. Tal y como sostiene Aleu (2017):

"Sobre la base de este principio universal, las democracias modernas como formas sociales singulares configuraron un modo de comprender la igualdad y la libertad que terminó por inscribirse en lo más profundo de los intercambios cotidianos y ha informado los sentidos y representaciones que se despliegan en las demandas de respeto" (p.51)

Una de las organizaciones donde esta institución de la igualdad se concreto fue la escuela. Los sistemas educativos modernos, como parte del entramado burocrático de los Estados Nacionales, se basaron en esta idea de igualdad y, a la vez, fueron los encargados de concretarla. Asumiendo la igualdad esencial -traduciéndola como igualdad ante la ley, como igualdad de oportunidades-captaron a porciones importantes de las nuevas generaciones y las instituyeron en tanto ciudadanos con derechos civiles, políticos y sociales similares; transmitiéndoles, y haciéndolos parte, de una cultura común.

En el caso de nuestro país, este proceso aconteció primordialmente con la escuela primaria, pues el nivel secundario, en los inicios de nuestro sistema educativo, tuvo un mandato más vinculado a la educación de las elites y a la selección de pobres meritorios, que a una genuina vocación universalista. No obstante, esto, la masificación de la escolaridad secundaria a fines del siglo pasado y la sanción de su obligatoriedad ha implicado que este nivel también tengan que asumir y hacerse cargo -no sin dificultades ni contradicciones- de concretar esa igualdad esencial.

En este sentido, considerar la actualidad de la Escuela Secundaria en Argentina implica asumir un conjunto de complejidades propios de una matriz instituida en otro contexto histórico, con otros fines político-pedagógicos, que se encuentra tensionada por nuevas demandas polí- 


\section{N V E S T I G A C I Ó N}

ticas y sociales que le exigen redefinirse en múltiples planos para incluir a sujetos pedagógicos para los que no estuvo pensada en sus orígenes (Tenti, 2000). Sujetos que, en el caso de los chicos y chicas de sectores populares, se encuentran atravesados por múltiples desigualdades materiales y simbólicas.

Según señala Núñez (2013) hoy asistiríamos a una “dislocación” en el vínculo escuela secundaria-jóvenes. Dislocación que se expresa, fundamentalmente, en la discordancia de las expectativas que tienen jóvenes y adultos respecto de la definición del espacio escolar, sus funciones y fines. Uno de los efectos centrales de esta dislocación -que es transversal a los diferentes sectores sociales, pero que se muestra con más virulencia en las instituciones a la que asisten chicos y chicas de sectores populares- es la dificultad de definir y consensuar los marcos de interacción cotidianos en las escuelas. Esta corrosión de los consensos alcanza -entre otros aspectos-a las definiciones acerca de qué es un trato respetuoso, a quién se le debe respeto, a quién no, cómo debe dispensárselo, etc.

El abordaje de esta noción es por demás compleja e implica considerar diferentes planos de análisis. Sennett (2003) distingue tres dimensiones a tener en cuenta: una dimensión subjetiva, o el respeto por uno mismo; una dimensión social, o el respeto en tanto honor o estima social; y una dimensión intersubjetiva, o el respeto en cuanto modalidad de trato o trabajo expresivo. Entender cómo viven y significan chicos y chicas de sectores populares los vínculos de respeto con sus docentes implica atender esta compleja trama.

\section{SENTIDOS QUE ADQUIERE LA IDEA DE RESPETO PARA LAS Y LOS JÓVENES EN EL VÍNCULO CON SUS DOCENTES}

Las y los jóvenes de sectores populares que asisten a escuelas secundarias de la Ciudad de San Luis encuestados y entrevistados en el marco de esta indagación, parecen señalar sentidos diferentes, y hasta divergentes, acerca de la noción de respeto. En este sentido es posible identificar dos grandes núcleos de sentido con presencias desiguales pero significativas. Siguiendo, en parte, una categorización propuesta por Deutsch y Jones (2008) al primero de estos núcleos le llamaremos respeto tradicional o unidireccional; al segundo, respeto emergente o bidireccional.

\subsection{Respeto tradicional o unidireccional}

Esta noción de respeto, que apareció con menor frecuencia deja entrever que para estos jóvenes el respetar implica ajustar sus conductas a un imperativo moral de obediencia y subordinación a sus adultos/as educadores/as y al entramado institucional que estos representan. Este respeto es unidireccional porque implica una sola dirección y, se podría agregar, una única obligación: el respeto es de las y los estudiantes hacia el mundo adulto, sin que haya un compromiso en devolver conductas equivalentes por parte de estos; $y$ es tradicional porque esta modalidad refleja el orden adultocéntrico propio de la escolaridad moderna donde la autoridad fue atributo exclusivo de uno de los polos del vínculo pedagógico, el encarnado por el/la docente.

En este sentido varios chicos y chicas plantean que respetar es, por un lado, obedecer sin cuestionamientos al docente: "hacer las tareas que los profes nos mandan”, "no contestar cuan- 


\section{N V E S T I G A C I Ó N}

do el profesor nos dice algo", "no insultar a los profes", "no picudear", "no hablar ni discutir en la clase”, etc.; y, por otro lado, regirse por la normatividad escolar sin transgredirla: "venir con el uniforme", "entrar al aula cuando tocan el timbre”, "no ratearse"4, "darle bola a las preceptoras cuando nos dicen que no corramos en el patio", etc.

Los argumentos que dan para justificar estas respuestas resultan, en algunos casos, tautológicos y, por ello, parecen dar cuenta de cierta legitimidad aún presente en el mundo adulto para hacerse obedecer y generar reconocimiento: "no se les contesta a los profesores porque son mayores"; "yo respeto porque en mi familia me enseñaron a respetar a los adultos"; "los profesores son grandes, saben, tiene experiencia por eso hay que hacerles caso... hay que respetarlos igual que en la familia con los padres”.

Si bien no lo hemos indagado específicamente en este trabajo, vale destacar que -según lo señala Núñez (2007) - esta idea de respeto como obediencia al orden escolar y sus representantes coincide con el sentido que suelen sustentar, en su mayoría, las y los profesores de secundario para quienes el respeto tiende a ser "respeto a la autoridad escolar". Por lo cual hay expectativas recíprocas coincidentes que facilitan la interacción adultos/as-jóvenes: unos demandan obediencia, otros la otorgan. En contraposición a esto, la conflictividad emerge cuando las expectativas recíprocas sobre quién debe respetar a quién y cómo debe actuar para hacerlo son divergentes.

\subsection{Respecto bidireccional o emergente}

La idea de un respeto bidireccional o emergente apareció en la mayoría de los testimonios analizados. Si bien, por las características de este trabajo, no realizamos una aproximación cuantitativa a los dichos de estos jóvenes que nos permita sostener esta afirmación con evidencia estadística, el análisis del corpus empírico sugiere claramente que esta noción de respeto está en la base de la mayoría de las encuestas y entrevistas.

A diferencia de lo planteado en el punto anterior esta noción de respeto es bidireccional porque hace alusión a un vínculo que, para que se constituya como tal, exige una devolución de las acciones respetuosas por parte de las y los sujetos involucrados. Aquí el respeto no es visto como un imperativo moral o una obligación unidireccional hacia un orden institucional o figura de autoridad, sino como una especie de contraprestación que debe fluir en ambos sentidos de la relación. "Respeto si me respetan...” resulta la frase arquetípica en este sentido. En efecto, la capacidad de mando por parte del/la docente y la obligación de obediencia estudiantil aparecen condicionadas a un intercambio de conductas que se concretan en ciertas modalidades de trato que las y los estudiantes consideran ineludibles para que ellos/as, a su vez, dispensen respeto. Por otra parte, nominamos a esta noción como emergente porque, a diferencia de la anterior, no es el sentido de respeto instituido tradicionalmente en el orden escolar. Donde el respecto es un prerrogativa del/la docente y de los símbolos propios del orden Escolar-Estatal.

Contradecir, contrariar de manera insolente.

4 Faltar sin permiso y/o escaparse de la escuela. 


\section{N V E S T I G A C I Ó N}

Ahora bien, las conductas exigidas por parte de estos jóvenes hacia las/los adultos como contraprestación necesaria para que ellos/as, a su vez, dispensen respeto son de variada índole. En un primer acercamiento y caracterización hemos podido identificar demandas de respecto que se concretan en: modalidades de trato formal; modalidades de trato pedagógico; modalidades de trato que incorporan aspectos personales-afectivos; modalidades de trato que no minusvaloren la identidad.

\subsubsection{Respeto por modalidades de trato formal}

La forma en que las y los docentes tratan a sus estudiantes parece cobrar especial relevancia para estos/as jóvenes. En este sentido las modalidades de trato valoradas se concretan, en general, en alusiones a como las y los adultos/as con quienes se relacionan en la escuela se comunican con ellos/as: el tono de voz que emplean, el tipo de palabras que usan y cómo las usan son mencionadas frecuentemente:

“...me siento respetada cuando la profe me trata de usted..."; "Nos respetan cuando se dirigen correctamente hacia nosotros"; “...no me siento respetado cuando se dirigen a mí de mala manera y no me hablan bien y tranquilo...”.

En contraposición a esto el "grito” aparece como característico del trato irrespetuoso:

“... acá no nos respeta nadie porque nos viven gritando como si fuéramos sus hijos...”; "no me respetan cuando me faltan el respeto, cuando me gritan o tratan mal...”; "no me siento respetado cuando contesta agresivamente...”; “... no me respetan: a veces te gritan como quieren o suben demasiado el tono de voz...”.

Es en este marco general que la forma de trato respetuosa parece hacerse digna de una contraprestación en el mismo sentido:

“...yo respeto a los profes que me hablan bien...”; “... yo creo que el respeto es hablar bien con la otra persona, amablemente, de una forma cordial por decirlo así, no con malas actitudes ni malas caras, por eso si un profe pretende que los escuchemos él nos tiene que escuchar a nosotros...”.

Finalmente, vale remarcar, estas modalidades de conducta adquieren importancia porque, como lo señala Sennet (2003), el respeto es un comportamiento fundamentalmente expresivo, en el sentido de que no sólo hay que sentirlo si no hay que saber exteriorizarlo en la interacción a través de los gestos apropiados puestos en juego en el momento justo. En este marco adquiere sentido lo manifestado por un estudiante cuando plantea: "siento el respeto cuando me lo transmiten...”.

\subsubsection{Respeto por modalidades de trato pedagógico}

Otra forma en que el mundo adulto parece vehiculizar expresiones de respeto valoradas por las y los jóvenes es a través del trabajo pedagógico, más específicamente, de un particular modo de encarar el trabajo pedagógico. A diferencia de lo analizado anteriormente, en este caso se trata 


\section{N V E S T I G A C I Ó N}

de una modalidad de trato respetuoso específica del espacio escolar en tanto trasciende los aspectos formales e involucra un contenido particular: las prácticas de enseñanza.

Si bien no se puede identificar una modalidad de enseñanza claramente delineada, las voces de las y los estudiantes sí evidencian una diferenciación entre acciones pedagógicas respetuosas e irrespetuosas vinculadas a como se desarrolla el trabajo docente:

“...me respeta cuando hace bien su trabajo, cuando da bien la tarea y no se distrae con el celular... la de Naturales hace eso, no nos da bola, eso me parece cualquiera, no te está respetando ahí...”.

En este contexto de valoración el aspecto que más destacan de un trabajo pedagógico "bien hecho" es la perseverancia en las explicaciones:

“...tiene que explicar bien cuando uno no entiende...”; “...me respeta cuando me explica y tiene paciencia...”; “...la de matemática no me respeta porque no explica bien y nos hace llevar la materia...”; “...el profe no nos quiere explicar las cosas por segunda vez, eso para mí es falta de respeto...”.

La habilitación del diálogo e intercambio de opiniones también es un rasgo destacado:

“...la de lengua siempre tiene la razón y cuando la contradecís te trata mal, eso no es respetar...”, “está bueno que te dejen hablar, uno y otro, que te diga pero que también puedas dar tu opinión y no se enoje. Ahí sí nos respetamos...”; “...No me respetan cuando no me dejan dar la opinión, cuando no me escucha y me dicen que todo lo que digo está mal...”.

Una buena síntesis de este trato pedagógico respetuoso -que, seguramente, involucra más aspectos que los aquí identificados- pueda resumirse en lo expresado por un estudiante quien señaló que las prácticas de enseñanza que lo respetan son aquellas realizadas “...con ganas, con amor y paciencia...”.

\subsubsection{Respeto por modalidades de trato que incorporan lo personal/afectivo}

No sólo los aspectos formales del vínculo o los aspectos pedagógicos parecen ser indicadores de un trato respetuoso, sino también la consideración de las y los chicos como personas más allá de su rol estrictamente institucional. Aquí el trato respetuoso incorpora un conjunto de situaciones, demandas e interacciones que trascienden lo escolar en sentido estricto y que reclaman de las y los docentes que "te den bola para hablar de cosas personales, de la vida".

Esta incorporación de lo personal parece implicar, por un lado, la escucha y la comprensión:

“...me respeta cuando me escucha o presta atención a lo que digo...”; “te respetan si te comprenden, no sos un robot que sólo viene a hacer la tarea. A veces venís con kilombos ${ }^{5}$ de tu casa y no tenés ganas de hacer nada...”.

5 Problemas, preocupaciones. 


\section{N V E S T I G A C I Ó N}

Por otro lado, en el contexto de este intercambio, chicos y chicas destacan el valor que adquiere compartir experiencias o dar consejos:

“...respeto a los profes piolas 6 , a los que escuchan, a los que te tratan bien, a los que te enseñan cosas que te sirven para la vida, a los que te dan consejos...”; “...respeto a los que comparten la ideología de la vida, que comparten sus experiencias y malas decisiones...”.

Dos salvedades resultan importantes de ser hechas en cuanto a esta incorporación de los aspectos personales. Por un lado, el hecho de que, para que esta incorporación funcione, debe darse en el marco de un clima de confianza interpersonal que, claramente, no se tiene con todos los adultos/as educadores/as y que parece exigir, por parte de estos, la construcción artesanal de un vínculo afectuoso. Caso contrario la alusión a la vida o el intento de aconsejar puede verse como una intromisión que no corresponde: "respeto es que no se metan en lo que no les importa, porque son cosas tuyas, de tu vida”.

Por otro lado, esta incorporación de lo personal no parece resultar equivalente para el caso de docentes y estudiantes. Si bien se valora el hecho de que las y los docentes -0 , al menos, algunos de ellos, con los que se tiene más confianza- hablen de su vida, este hablar no implica que puedan traer sus problemas personales al aula "algunos vienen calientes ${ }^{7}$ porque tienen problemas en su casa y se la agarran con uno, te retan sin que hagas nada...”. En este sentido se podría decir que el deber de comprensión y escucha de la situación vital del otro parece ser, para estos estudiantes, una responsabilidad de las y los adultos que no admite reciprocidad.

\subsubsection{Respeto por modalidades de trato que no minusvaloran la identidad}

Un último aspecto que pudimos identificar tiene que ver con aquellas acciones realizadas por docentes que, desde el punto de vista juvenil, afirman o menoscaban su identidad. Eso es, el modo en que ellos/as definen su ser y aparecer (en el sentido de cómo se muestran, se exhiben) en el contexto escolar. Ser y aparecer que parece estar vinculado, por un lado, con las formas en que se presentan en la vida cotidiana a partir de la vestimenta o de ciertos consumos culturales y, por otro lado, por cómo es valorada esa identidad por las y los docentes, y el impacto que esa valoración tiene sobre la autoimagen.

Como lo han señalado varias investigaciones que indagan el campo de las culturas juveniles (Tenti, 2000; Kantor, 2012; entre otros), los modos de aparecer y los consumos culturales son constitutivos de las identidades juveniles, por ello resulta relevante para estos jóvenes -en clave de sentirse respetados o irrespetados- el modo en que las y los adultos actúan valorando o no estas construcciones. En efecto, varios testimonios parecen sugerir la importancia de la ropa:

"No nos respetan cuando se burlan de nuestros gustos, cuando nos discriminan por la apariencia, por ejemplo, por como uno esta peinado...”; “... no me respetan porque me hacen venir vestido como

6 Simpático, sociable.

7 Enojados, irascibles. 


\section{N V E S T I G A C I Ó N}

ellos quieren...”; “la de lengua me bardeó ${ }^{8}$ por el pircing, me decía que parecía un animalito, eso no es respetar...”.

Y de algunos consumos culturales como la música: "la profe no se bancó9 que me hiciera la cresta, no me respeta porque soy punk...”. Lo que parece estar por detrás de estos testimonios es una demanda de reconocimiento al mundo adulto del modo en que ellos/as definen su identidad.

Por otra parte, asociado a este mismo tema, también parece surgir cierta inquietud o queja cuando esta identidad es minusvalorada comparativamente por las y los docentes:

“...no me respetan cuando dicen que uno es menos que otro alumno, o sea nos hacen bajar nuestra autoestima como estudiantes...”; “... no me respeta el de educación física: me hace sentir menos porque no tengo el mismo rendimiento que otros compañeros, nos compara con los varones o con otras alumnas. Una no es mejor o peor por tener más o menos rendimiento, podría ver que ponemos mucho esfuerzo en vez de tratarnos mal porque no rendimos lo que el quiere...”.

\section{A MODO DE CONCLUSIÓN: DIGNIDAD, IGUALDAD Y RECIPROCIDAD EN EL VÍNCULO INTERGENERACIONAL}

Para concluir este trabajo quisiéramos realizar una lectura -a modo de hipótesis para seguir pensando-sobre algunos supuestos que, a nuestro criterio, podrían estar en la base de estas demandas de trato respetuoso planteadas por las y los jóvenes. Para hacerlo intentaremos significar los testimonios haciéndolos dialogar con algunos aportes teóricos que nos resultan especialmente significativos para comprender la problemática planteada.

Hablar de respeto en los vínculos inter-generacionales que se tejen en la escuela -particularmente en la escuela secundaria-implica atender al modo en que las y los jóvenes definen su dignidad personal y cómo esta definición entra en tensión con el trato que reciben por parte de sus adultos/as educadores/as.

Desde el punto de vista jurídico, particularmente luego de la declaración de los derechos humanos, la idea de dignidad hace alusión al valor inherente al ser humano por el simple hecho de serlo, en cuanto ser dotado de racionalidad, libertad e igualdad ante sus pares. Como señalamos anteriormente, el desarrollo de las sociedades occidentales ha implicado la difusión de esta noción de dignidad al punto de permear íntimamente las imágenes de sí construidas por los sujetos, y lo que estos esperan de sus interacciones cotidianas en las diferentes instituciones de las que forman parte. Aún aquellas que, por su misma definición, se estructuran en función de vínculos asimétricos o desiguales, como la escuela o la familia. En este sentido, la difusión de esta lógica igualitarista entra en tensión con la estructuración y el funcionamiento mismo de estas instituciones. Siguiendo a Todorov (2007) podríamos relacionar el concepto de dignidad con el problema de la autonomía personal, para este autor: 


\section{N V E S T I G A C I Ó N}

Tomo una decisión y actúo de acuerdo a ella. He ahí en qué consiste mi dignidad. El ejercicio de la voluntad es uno de los ingredientes de esta virtud; el otro es la concordancia entre interior y exterior [...] se puede definir la dignidad como la capacidad de satisfacer mediante los propios actos los criterios que uno ha interiorizado. La dignidad se convertiría entonces en sinónimo de respeto a uno mismo (p. 73).

En efecto, por un lado los testimonios de las y los jóvenes parecen sugerir que cuando hablan de respeto o irrespeto señalan el modo en que definen su dignidad personal y lo que hacen para actuar en concordancia con esta definición en el plano personal e interpersonal. Por otro lado, también muestra cómo esta definición entra en tensión con la institucionalidad escolar y los vínculos que establecen con los adultos/as educadores/as ${ }^{10}$. En este sentido se podría plantear que el nudo de la cuestión pasa por considerar cómo la dinámica escolar y la relación con las figuras de autoridad instituidas promueven o complican la experiencia del respeto a sí mismo en las y los jóvenes. Refrendando lo planteado en el marco teórico, varios testimonios sugieren que estos chicos y chicas se ven a sí mismos como “esencialmente” iguales a los/as adultos/as, de ahí que demanden modalidades de trato acordes a este supuesto:

“...yo pienso que somos todos iguales, ellos se merecen respeto tanto como yo...”; “.... Me tiene que respetar como yo a él porque nosotros también somos autoridad en la escuela...”; “... respeto a los profesores que me respetan a mí. Todos somos iguales, ninguno es más ni menos, algunos tendrán más poder, pero no es motivo para faltar el respeto a nadie. Creo que algunos docentes tendrían que poner muy en práctica la palabra respeto...”; “... me respeta por el simple hecho de ser persona como él...”.

Dicho esto, vale puntualizar un aspecto central: estamos hablando de jóvenes pertenecientes a sectores populares atravesados por desigualdades de clase, etnia, género y generación, y sujetos a fuertes procesos de estigmatización e inferiorización social (Kaplan y Silva, 2016). Si entendemos que la estima o el respeto otorgado socialmente es un bien simbólico desigualmente distribuido podemos comprender la dificultad que tienen estos jóvenes de articular experiencias de respeto a sí mismos. En este marco se pueden interpretar expresiones como:

“...no me respeta cuando nos dice que somos drogadictos sin conocer; el primer día nos dijo eso y que estábamos todo el día en la calle...”; “...para mi respetar es comprender y valorar a la otra persona, porque tampoco es menos por ser de este barrio o por su color de piel y esas cosas...”.

Pensando en la fragilidad de la identidad social de jóvenes norteamericanos pobres Sennett (2003) plantea algo que resuena en estas afirmaciones de los chicos y chicas encuestados:

...los adolescentes del gueto son muy sensibles al hecho de que no se les respete. En los sitios donde los recursos son escasos y falta la aprobación del mundo exterior, el honor social el frágil: necesita afirmarse día a día (p. 47).

10 Si bien no lo abordamos en este trabajo, vale recalcar que también resulta fundamental considerar en este sentido el peso subjetivo que tiene el vínculo con los pares y no sólo con sus docentes. 


\section{N V E S T I G A C I Ó N}

Finalmente, una breve mención al problema de reciprocidad. La presencia significativa de lo que hemos llamado respeto bidireccional nos habla de la importancia de considerar las dinámicas de reciprocidad en el ámbito escolar si se quiere promover un clima que favorezca los procesos de enseñanza-aprendizaje y la re-apropiación por parte de estos/as jóvenes de la herencia cultural que se les pretende transmitir.

En este sentido un joven manifestaba: “...los respeto porque ellos me están enseñando algo que no sé, y si ellos me tratan bien a mí y a mis compañeros yo les voy a brindar mi respeto...”. Construir una sensibilidad en torno de las acciones recíprocas necesarias para que las y los estudiantes se sientan respetados implica una posición de apertura y exploración por parte de las y los adultos educadores/as que les posibilite encontrar o producir los gestos y modalidades de trato necesarias para que esto sea posible.

Apertura, exploración y sensibilidad que, en el actual escenario de cambio en las relaciones inter-generacionales, parecen funcionar como condiciones de posibilidad necesarias, más no suficientes, para conjurar la tensión propia del (¿des?) encuentro generacional en estos tiempos de cambios escolares y, agregaríamos, civilizatorios.

\section{REFERENCIAS}

Aleu, M. (2008). Las concepciones de autoridad en los estudiantes de la escuela media. Tesis de Maestría en Educación. Argentina - Universidad de San Andrés.

Aleu, M. (2017) Los vínculos de respeto en la educación de jóvenes y adolescentes. Tesis Doctoral. ArgentinaUniversidad de Buenos Aires. Disponible en: https://bit.ly/34d41bf

Bourgois, P. (2015) En busca de respeto. Vender crack en Harlem. Argentina-Siglo XXI Editores.

Deutsch, N.; Jones, S. (2008). "Show Me an Ounce of Respect": Respect and Authority in Adult-Youth Relationships in After-School Programs”. En Journal of Adolescent Research. Vol. 23 (N. 6) pp. 667688. DOI: $\underline{\text { https://doi.org/10.1177/0743558408322250 }}$

Kaplan, K.; Silva, M. (2016) "Respeto y procesos civilizatorios. Imbricación socio-psíquica de las emociones”. En Praxis educativa, Vol. 20 (№ 1), pp. 28-36.

DOI: https://doi.org/10.19137/praxiseducativa-2016-200103

Nuñez, P. (2007) “Los significados del respeto en la escuela media”. En Propuesta Educativa Vol. 1 (N.27), pp. $80-87$. https://bit.ly/2JGqrIe

Nuñez, P. (2013) La política en la escuela. Argentina-La Crujia.

Paulín, L.; Martínez, S. (2014) “Sentido y acciones en procura de respeto en la escuela”. En Paulín, L. "Jóvenes y Escuela. Relatos de una relación compleja" (pp. 45 - 72). Argentina - Editorial Brujas.

Rosales, G. (2013) "De autorizantes, autorizados y autorizaciones. Procesos de construcción de autoridad pedagógica en experiencias educativas desarrolladas con jóvenes de sectores populares". Tesis Doctoral. España -Universidad de Málaga. Disponible en: https://bit.ly/2RbZvnW

Sennett, R. (2003) El respeto. Sobre la dignidad del hombre en un mundo desigual. España-Anagrama. 
maroenes

\section{N V E S T I G A C I Ó N}

Silva, V. (2018) "La demanda por un buen trato en la escuela secundaria”. En Educação \& Realidade, Vol. 43 (N. 2), pp 35-57. DOI: 10.1590/2175-623662538

Tenti Fanfani, E. (2000) Culturas juveniles y cultura escolar. Argentina-IIPE/UNESCO.

Todorov, T. (2007) Frente al límite. España-Siglo XXI Editores

Todorov, T. (2008) La vida en común. Ensayo de antropología general. Argentina-Taurus. 